\title{
Cervical myelopathy due to a solitary osteochondroma: a case report
}

\author{
Toru Asari, Naoki Echigoya, Norihiro Sasaki, Gentaro Kumagai and Kazumasa Ueyama
}

\begin{abstract}
Introduction: Osteochondroma is the most common benign bone tumor. However, the incidence of osteochondroma in the spine is reported to be very rare.

Case description: This report presents the case of a 57-year-old man who suffered from osteochondroma of the cervical spine. He had bilateral lower extremity pain for 3 years, developing pain of right upper extremity and gait disturbance. Plain radiographic images and computed tomography scans showed bony lesion in right C6/7 foramen and C6 lamina. Magnetic resonance images of whole spine showed severe compression of spinal cord at the C6/7 and spinal canal stenosis at the L3/4 level. First, we performed a surgery of the cervical spine, and removed the tumor covered with the cartilaginous cap. The pathological diagnosis of the tumor was osteochodroma. After the surgery, the symptoms on his right upper extremity improved smoothly. Because the bilateral lower extremity pain remained, a L3/4 partial laminectomy was performed 1 month later, and the symptom improved. At 1 year after his primary operation, we could not find a recurrence of the tumor.
\end{abstract}

Conclusions: It is very important to perform a complete en bloc resection of the tumor (especially cartilaginous cap) to prevent the recurrence.

Keywords: Osteochondroma, Exostoses, Cervical myelopathy, Surgical treatment

\section{Introduction}

Osteochondroma is frequently located in the metaphysis of the long bones, and it is an ectopic development of cartilage growth plate. This tumor constitutes 10-15\% of all bone tumors and $20-50 \%$ of benign bone tumors (Murphey et al. 2000). It typically occurs in young adolescent patients, because it is a disease of bone growth (Brastianos et al. 2005). We frequently treat this tumor in the proximal humerus, distal femur and metaphysis of tibia. However, the incidence rate of the tumor in the spine is very rare, only approximately $3 \%$ (Khosla et al. 1999). In this report, we demonstrate a case of cervical myelopathy due to this rare tumor with a review of the literature.

\section{Case report}

A 57-year-old man had suffered from low back and bilateral lower extremity pain for 3 years, and had been

\footnotetext{
*Correspondence: toru.asari.miami@gmail.com

Department of Orthopaedic Surgery, Hirosaki Memorial Hospital, 59-1 Sakaizeki-nishida, Hirosaki, Aomori 036-8076, Japan
}

diagnosed with lumbar disc herniation by a general practitioner. He had a history of hyperlipemia and diabetes. However his symptoms were getting worse, and he developed additional symptoms: right upper extremity pain, and gait disturbance. He went to a nearby orthopedic clinic, and was soon referred to us for additional examination and treatment. His neurological examination revealed numbness in the right forearm and both thighs. Weakness of the interosseous muscle on the right side was detected, with grade of $4 / 5$ recorded by manual muscle testing. His gait was very unstable, and he needed to be assisted by a walker. His right patellar tendon and Achilles tendon reflexes were hyperactive and the Hoffmann and Babinski reflex were positive. Laboratory values including full blood count, electrolytes, and inflammatory markers were all within normal limits.

The plain radiological findings of his cervical spine indicated an osseous protrusion in the right $\mathrm{C} 6 / 7$ foramen (Fig. 1). Computed tomography (CT) scans showed an osseous tumor originating in the neighborhood of the 


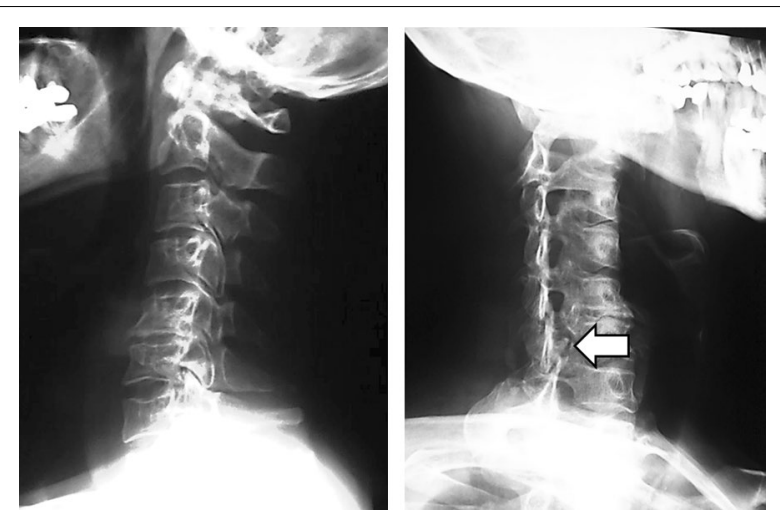

Fig. 1 Preoperative plain radiograph of the cervical spine. An osseous protrusion in the right C6/7 foramen could be observed

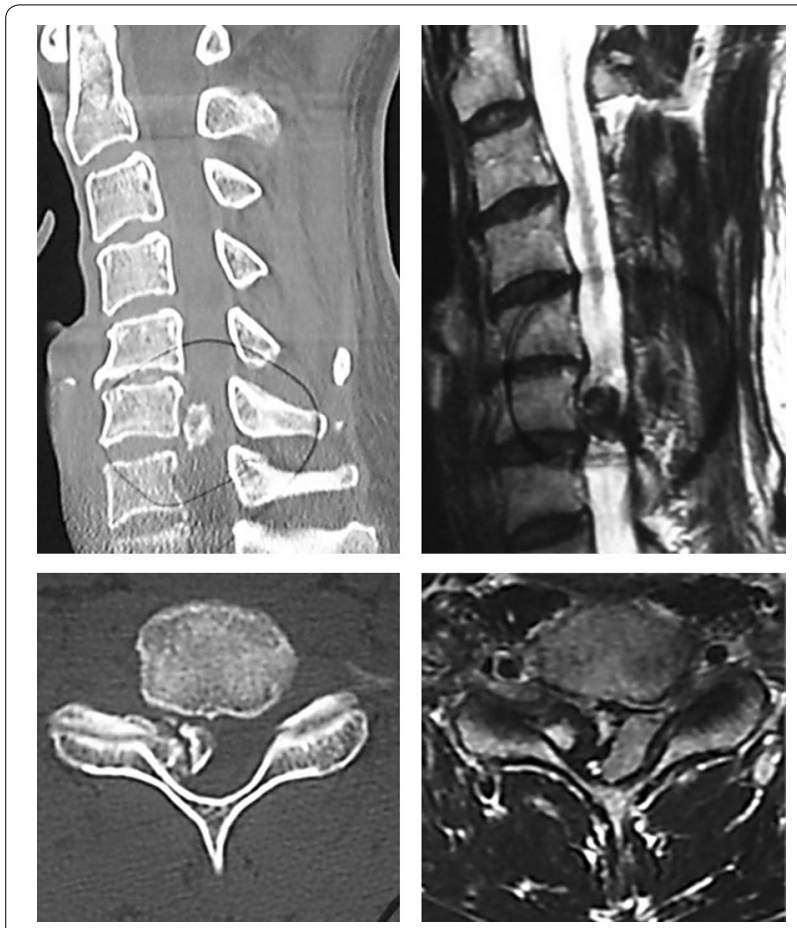

Fig. 2 Preoperative CT and MRI of the cervical spine. Sagittal and axial CT scans demonstrated an osseous tumor originating in the neighborhood of the right C6/7 facet joint. Sagittal and axial MRI revealed an extradural mass which compressed the spinal cord severely at C6/7 level

right C6/7 facet joint and occupying a part of the spinal canal (Fig. 2). Magnetic resonance images (MRI) revealed the compression of spinal cord at the $\mathrm{C} 6 / 7$ and spinal canal stenosis at the L3/4 level. The tumor was hypointense or isointense on T1-weighted and T2-weighted images.

We diagnosed him with cervical myelopathy caused by the compression of the spinal cord due to an intra-canal tumor, and performed a C6 laminectomy and a C7 partial laminectomy with posterior approach. The tumor did not show the adhesion to the dural membrane, and en bloc resection of the tumor was performed. The resected tumor was about $2 \mathrm{~cm}$ in diameter, and its surface was covered with cartilaginous tissue (Fig. 3). The pathologic examination indicated mature trabecular bone with a cartilaginous cap, and we had a diagnosis of a benign osteochondroma (Fig. 4). On the next day after the surgery, the pain on the right upper extremity was improved, but the symptoms on the lower extremities remained. Therefore,

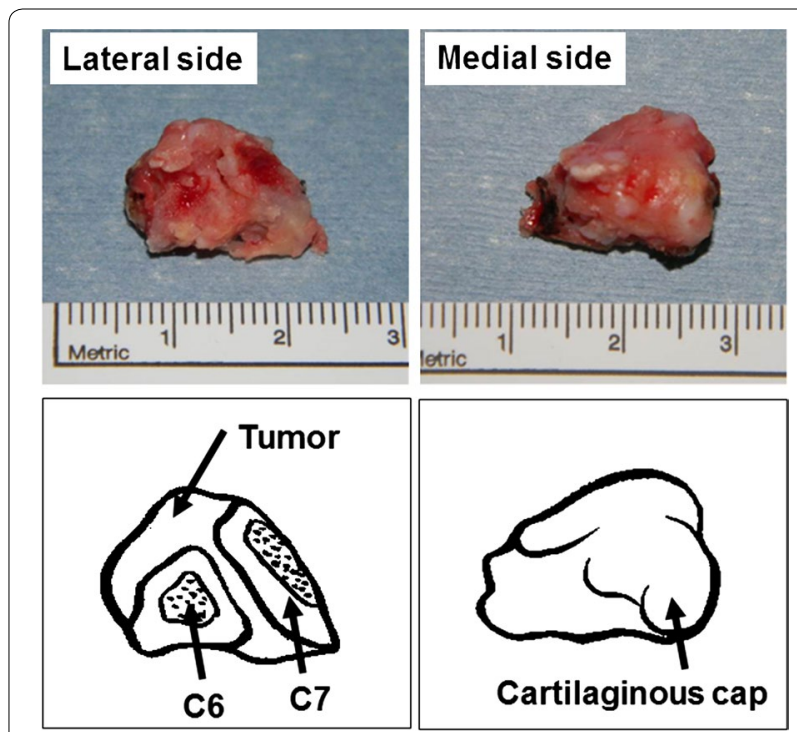

Fig. 3 Operative specimen was covered with cartilaginous tissue. The tumor originated from the neighborhood of the right C6/7 facet joint and occupied part of the spinal canal

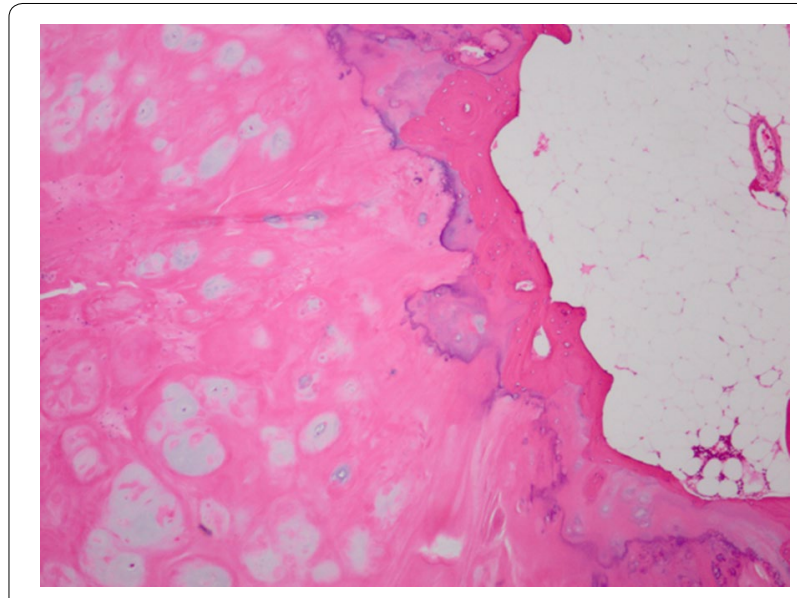

Fig. 4 Tumor pathology. Microphotograph of the specimen showed mature trabecular bone and fatty marrow capped by cartilaginous tissue $(\times 100$, hematoxylin and eosin) 
we performed a decompression of the spinal canal at L3/4 level 1 month later. And then the symptoms improved clearly. He was discharged from our hospital at 6 weeks after his first operation. Post-operative radiograph of the cervical spine did not show each segmental instability. Also, post-operative CT scan showed the removal of the lesion, and demonstrated that over $2 / 3$ part of the facet was preserved (Fig. 5). Recurrence was not observed at the time of examination 1 year after the first surgery.

\section{Discussion}

Osteochondroma may develop as a solitary or multiple lesions which are known as hereditary multiple exostoses (HME). The incidence rate of HME is about $12 \%$ of all osteochondromas (Gille et al. 2005). Particularly, the incidence of osteochondroma in the spine is reported to be very rare in the literature (Khosla et al. 1999). The spinal involvement of HME is about 7-9 \% (Giudicissi-Filho et al. 2006), whereas that of solitary osteochondroma is about 1-4 \% (Chooi et al. 2005). This tumor can occur in any vertebrae of the spine, but the cervical spine is commonly involved in about $50 \%$ (Murphey et al. 2000). The most frequent site is the $\mathrm{C} 2$ vertebral bone, followed by C3 and C6 (Chatzidakis et al. 2007; Maheshwari et al. 2006; Schomacher et al. 2009). Osteochondroma typically occurs in young patients, but those of the spine usually occur during the second to third decades of life (Bess et al. 2005; Sakai et al. 2002). Sakai et al. suggested that

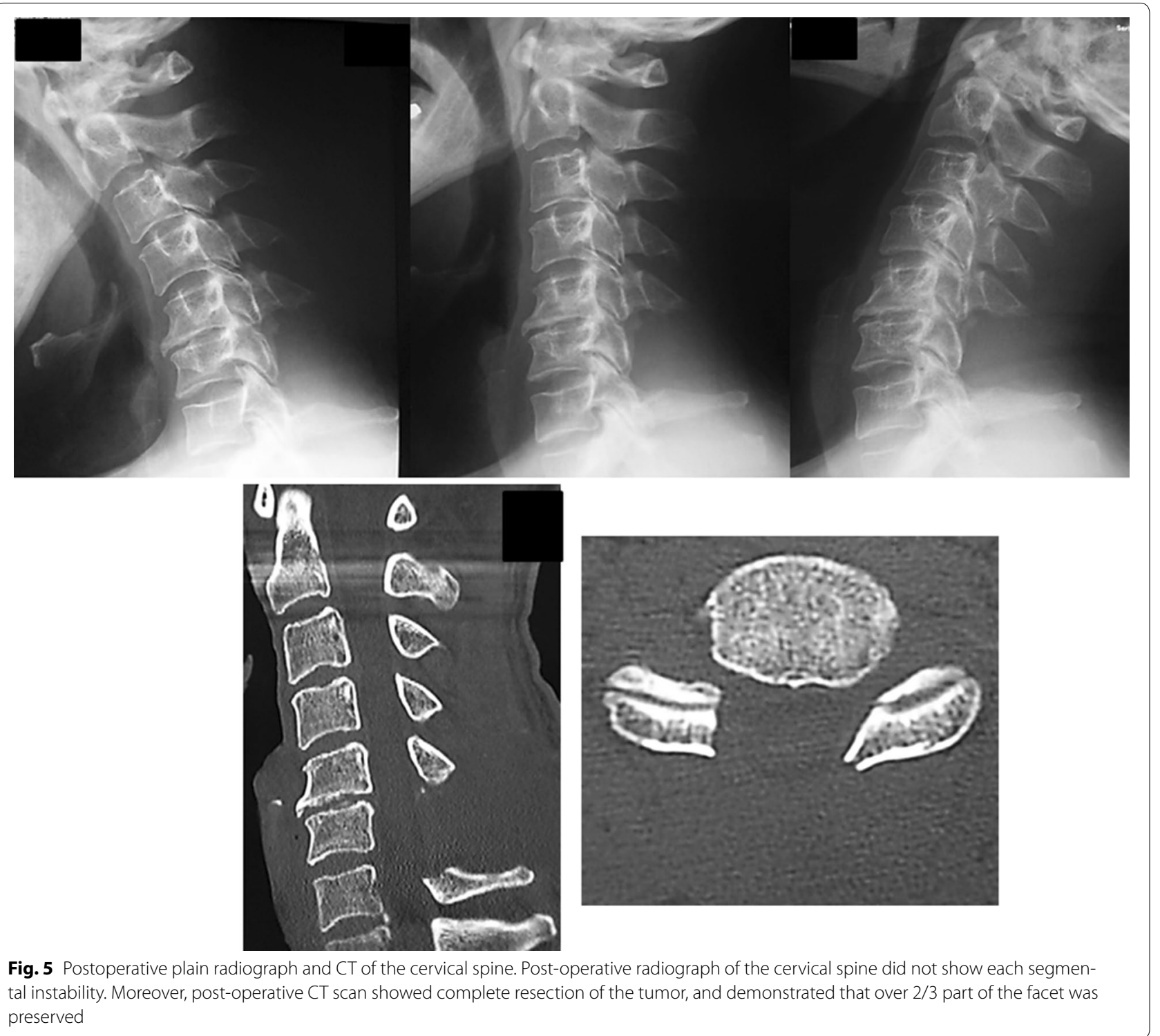


degenerative changes of the vertebrae might contribute to the initiation of symptoms in the elderly. Some authors reported that both multiple and solitary osteochondromas are more likely to be appeared in the male than the female (Gille et al. 2005; Labram and Mohan 1996). However, Zaijun et al. (2013) reported that female patients showed symptoms more frequently than male patients in solitary osteochondroma of the spine [9:3].

Osteochondroma of extremities typically forms a pedunculated or a sessile mass adjacent to the bone marrow and the cortex (Albrecht et al. 1992). The plain radiological finding is usually useful for the diagnosis with the osteochondroma of the extremities. However, an osteochondroma of the spine is difficult to detect on only plain radiological findings, because the osseous structures of the spinal column are very complex (Yukawa et al. 2001). Most of the lesions typically arise from the lamina or pedicles, but can rarely arise from the vertebral body (Khosla et al. 1999). Lotfinia et al. (2010) reported plain radiological findings helped to identify lesions in $50 \%$ of patients suffering from an osteochondoroma of the spine. Therefore both CT scan and MRI were recommended to detect the origin and size of the lesions with details. The CT scan can demonstrate the bony and cartilaginous components of the tumor, and is useful to clarify the zone of attachment of the tumor, contributing to preoperative planning (Sharma et al. 2002). The level and the extent of neural structure compression are best visualized on MRI. There are ossification of the ligamentum flavum (OLF) and bony spur as the lesions that we have to differentiate from osteochondroma. In East Asian countries, ossification of OLF is more common than in other countries. The prevalence of OLF was reported to be $3.8 \%$ (whole spine) in China, and $36 \%$ (thoracic only) in Japan (Guo et al. 2010; Mori et al. 2013). OLF is not commonly revealed at the cervical spine. It is possible to distinguish OLF from osteochondroma as the shape.

It was reported to be extremely rare that the osteochondroma of the spine compressed the spinal cord (Labram and Mohan 1996). The incidence of neurological symptoms including myelopathy and radiculopathy caused by the tumor was $0.5-1 \%$ (Brastianos et al. 2005; Ratliff and Voorhies 2000). Rare osteochondroma arising anteriorly from the cervical vertebral body can compress the surrounding tissues, and cause dysphagia (Grivas et al. 2005; Wong et al. 2013), sleep apnea (Wang and Chou 2009), respiratory distress, vocal cord paralysis (Certo et al. 2014), and Horner syndrome (Zhao et al. 2007). Moreover, Certo et al. (2014) reported the correlation between tumor development and presence of diffuse idiopathic skeletal hyperostosis. Symptomatic lesion needed to be treated surgically, and good results of the total resection were reported (Albrecht et al. 1992; Brastianos et al. 2005). The therapeutic option for an asymptomatic lesion is controversial. Some authors reported that the surgical intervention should be recommended when the spinal cord was compressed by the tumor (Aldea et al. 2006; Giudicissi-Filho et al. 2006; Wen et al. 1989). Sudden death caused by odontoid osteochondroma was reported (Rose and Fekete 1964).

The risk of recurrence is approximately $2-4 \%$ in osteochondroma of the spine (Bess et al. 2005; Gille et al. 2005). Pecker et al. (1980) reported a case of recurrence treated by curettage of the tumor lesion. Bess et al. (2005) described two cases of symptomatic recurrence after intralesional resection. The mean interval of the recurrence was 4.2 years. The malignancy usually originates from the cartilaginous cap (Lotfinia et al. 2010). Therefore, some authors recommend complete en bloc resection of the tumor (especially cartilaginous cap) should be done to reduce recurrence (Gille et al. 2005; Zaijun et al. 2013). Zaijun et al. (2013) reported two cases with recurrence had sarcomatous transformation. The incidence of malignant transformation is reported to be approximately $1 \%$ in a solitary osteochondroma and $10 \%$ in HME (Brastianos et al. 2005; Khosla et al. 1999). If the tumor originates from the facet, we may consider a stabilization of the spinal column to remove it completely (Albrecht et al. 1992; Yukawa et al. 2001). In our case, the stalilization was not necessary because over $2 / 3$ part of the facet joint was preserved.

\section{Conclusions}

We demonstrated the case of osteochondroma in the cervical spine that was treated with surgery. It is very important to perform a complete en bloc resection of the tumor (especially cartilaginous cap) to prevent the recurrence.

\section{Abbreviations \\ CT: computed tomography; MRI: magnetic resonance images; HME: hereditary multiple exostoses.}

\section{Authors' contributions}

TA drafted the manuscript. NE, NS, GK, KU helped to draft the manuscript. All authors read and approved the final manuscript.

\section{Competing interests}

The authors declare that they have no competing interests.

Consent

The patient has consented to the submission of the case report for the journal. Received: 27 October 2015 Accepted: 19 April 2016 Published online: 27 April 2016

References

Albrecht S, Crutchfield JS, SeGall GK (1992) On spinal osteochondromas. J Neurosurg 77:247-252 
Aldea S, Bonneville F, Poirier J, Chiras J, George B, Carpentier A (2006) Acute spinal cord compression in hereditary multiple exostoses. Acta Neurochir (Wien) 148:195-198

Bess RS, Robbin MR, Bohlman HH, Thompson GH (2005) Spinal exostoses: analysis of twelve cases and review of the literature. Spine 30:774-780

Brastianos P, Pradilla G, McCarthy E, Gokaslan ZL (2005) Solitary thoracic osteochondroma: case report and review of the literature. Neurosurgery 56:E1379

Certo F, Sciacca G, Caltabiano R, Albanese G, Borderi A, Albanese V, Migliore M, Barbagallo GM (2014) Anterior, extracanalar, cervical spine osteochondroma associated with DISH: description of a very rare tumor causing bilateral vocal cord paralysis, laryngeal compression and dysphagia. Case report and review of the literature. Eur Rev Med Pharmacol Sci 18(1 Suppl):34-40

Chatzidakis E, Lypiridis S, Kazdaglis G, Chatzikonstadinou K, Papatheodorou G (2007) A rare case of solitary osteochondroma of the dens of C2 vertebra. Acta Neurochir (Wien) 149:637-638

Chooi YS, Siow YS, Chong CS (2005) Cervical myelopathy caused by an exostosis of the posterior arch of C1. J Bone Joint Surg Br 87:257-259

Gille O, Pointillart V, Vital JM (2005) Course of spinal solitary osteochondromas. Spine 30:E13-E19

Giudicissi-Filho M, de Holanda CV, Borba LA, Rassi-Neto A, Ribeiro CA, de Oliveira JG (2006) Cervical spinal cord compression due to an osteochondroma in hereditary multiple exostosis: case report and review of the literature. Surg Neurol 66(Suppl 3):S7-S11

Grivas TB, Polyzois VD, Xarchas K, Liapi G, Korres D (2005) Seventh cervical vertebral body solitary osteochondroma. Report of a case and review of the literature. Eur Spine J 14:795-798

Guo JJ, Luk KD, Karppinen J, Yang H, Cheung KM (2010) Prevalence, distribution, and morphology of ossification of the ligamentum flavum: a population study of one thousand seven hundred thirty-six magnetic resonance imaging scans. Spine 35:51-56

Khosla A, Martin DS, Awwad EE (1999) The solitary intraspinal vertebral osteochondroma. An unusual cause of compressive myelopathy: features and literature review. Spine 24:77-81

Labram EK, Mohan J (1996) Diaphyseal aclasis with spinal cord compression. Report of two cases and review of the literature. J Neurosurg 84:518-521

Lotfinia I, Vahedi P, Tubbs RS, Ghavame M, Meshkini A (2010) Neurological manifestations, imaging characteristics, and surgical outcome of intraspinal osteochondroma. J Neurosurg Spine 12:474-489

Maheshwari AV, Jain AK, Dhammi IK (2006) Osteochondroma of C7 vertebra presenting as compressive myelopathy in a patient with nonhereditary (nonfamilial/sporadic) multiple exostoses. Arch Orthop Trauma Surg 126:654-659
Mori K, Kasahara T, Mimura T, Nishizawa K, Murakami Y, Matsusue Y, Imai S (2013) Prevalence, distribution, and morphology of thoracic ossification of the yellow ligament in Japanese: results of CT-based cross-sectional study. Spine 38:E1216-E1222

Murphey MD, Choi JJ, Kransdorf MJ, Flemming DJ, Gannon FH (2000) Imaging of osteochondroma: variants and complications with radiologic-pathologic correlation. Radiographics 20:1407-1434

Pecker J, Vallee B, Desplat A, Guegan Y (1980) Lateral interscalenic approach for tumors of the cervical intervertebral foramina (author's transl). Neurochirurgie 26:165-170

Ratliff J, Voorhies R (2000) Osteochondroma of the C5 lamina with cord compression: case report and review of the literature. Spine 25:1293-1295

Rose EF, Fekete A (1964) Odontoid osteochondroma causing sudden death. Report of a case and review of the literature. Am J Clin Pathol 42:606-609

Sakai D, Mochida J, Toh E, Nomura T (2002) Spinal osteochondromas in middle-aged to elderly patients. Spine 27:E503-E506

Schomacher M, Suess O, Kombos T (2009) Osteochondromas of the cervical spine in atypical location. Acta Neurochir (Wien) 151:629-633

Sharma MC, Arora R, Deol PS, Mahapatra AK, Mehta VS, Sarkar C (2002) Osteochondroma of the spine: an enigmatic tumor of the spinal cord. A series of 10 cases. J Neurosurg Sci 46:66-70

Wang V, Chou D (2009) Anterior C1-2 osteochondroma presenting with dysphagia and sleep apnea. J Clin Neurosci 16:581-582

Wen DY, Bergman TA, Haines SJ (1989) Acute cervical myelopathy from hereditary multiple exostoses: case report. Neurosurgery 25:472-475

Wong K, Bhagat S, Clibbon J, Rai AS (2013) "Globus symptoms": a rare case of giant osteochondroma of the axis treated with high cervical extrapharyngeal approach. Glob Spine J 3:115-118

Yukawa Y, Kato F, Sugiura H (2001) Solitary osteochondroma of the lower cervical spine. Orthopedics 24:292-293

Zaijun L, Xinhai Y, Zhipeng W, Wending H, Quan H, Zhenhua Z, Dapeng F, Jisheng Z, Wei Z, Jianru X (2013) Outcome and prognosis of myelopathy and radiculopathy from osteochondroma in the mobile spine: a report on 14 patients. J Spinal Disord Tech 26:194-199

Zhao CQ, Jiang SD, Jiang LS, Dai LY (2007) Horner Syndrome due to a solitary osteochondroma of C7: a case report and review of the literature. Spine 32:E471-E474

\section{Submit your manuscript to a SpringerOpen ${ }^{\odot}$ journal and benefit from:}

- Convenient online submission

- Rigorous peer review

- Immediate publication on acceptance

- Open access: articles freely available online

- High visibility within the field

- Retaining the copyright to your article

Submit your next manuscript at springeropen.com 